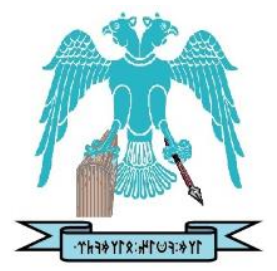

JOURNAL OF ENERGY SYSTEMS

$2020,4(4)$

\title{
Cost benefit analysis for peer-to-peer mechanism in residential sector of a single buyer electricity market
}

\author{
Aloysius Damar Pranadi \\ University of Indonesia, Faculty of Engineering, Tropical Renewable Energy Center, Indonesia, \\ damarpranadi@gmail.com \\ Eko Adhi Setiawan \\ University of Indonesia, Faculty of Engineering, Tropical Renewable Energy Center, Indonesia, \\ ekoas@eng.ui.ac.id
}

$\begin{array}{cr}\text { Submitted: } & 04.06 .2020 \\ \text { Accepted: } & 17.12 .2020 \\ \text { Published: } & 31.12 .2020\end{array}$

Abstract: Recently, feed-in-tariff (FIT) is no longer under government's preference due to fiscal support limits and reluctancy of utility to purchase RE-based electricity at higher price. Indeed, the absence of any incentives will significantly impact to renewable market growth. Therefore, net metering/billing implemented, but sometimes its price is unfairly offered in comparison with utility retail price. To seek more interesting model that can benefit to government utility and people, a so-called mechanism peer-to-peer (P2P) is proposed as alternative solution in this study. This study investigates an applicability of this new energy trading mechanism in vertically integrated unit electricity market (regulated market), by comparing this mechanism with the existing mechanism e.g. net metering/billing. The P2P was studied using a built-own optimization tool (in excel base) to determine its economic analysis, its market price and cost-benefit for utility and P2P participants. As a result, using P2P, each participant installing solar photovoltaic (solar PV) can fasten their payback period up to 2 years from its net metering payback, raise internal rate of return (IRR) by $2-3 \%$, obtain 500 US\$ net present value (NPV) for prosumer only (a consumer with electricity generator such as solar PV) and 3,000 US\$ for prosumer with storage system in comparison with its analysis with existing net metering. Besides, P2P also brings monetized benefits for a single-buyer utility than its lost market. This study also shows that P2P is institutionally feasible for regulated market with any restriction to sell electricity from non-utility entities.

Keywords: Fuzzy PI controller, Interleaved boost converter, PI controller, Soft switching

Cite this paper as:

Pranadi, A. D. and Setiawan, E. A. Cost benefit analysis for peer-to-peer mechanism in residential sector of a single buyer electricity market. Journal of Energy Systems 2020; 4(4): 179-195, DOI: $10.30521 /$ jes. 748138

(c) 2020 Published by peer-reviewed open access scientific journal, JES at DergiPark (https://dergipark.org.tr/en/pub/jes)

\begin{tabular}{r|l} 
Nomenclature & \\
DG & distributed generation \\
FIT & Feed-in Tariff \\
IRT & Internet, Communication and Technology \\
ICOE & Levelized cost of energy \\
MV & Market Value \\
NM & Net Metering \\
NPV & Net Present Value \\
O\&M & Operational and maintenance \\
P2P & Peer-to-peer \\
PP & Payback period \\
Solar PV or PV & Solar Photovoltaic \\
\hline \hline
\end{tabular}




\section{INTRODUCTION}

In recent years, global energy system faces a rapid change due to an emergence of distributed generation (DG) [1]. In traditional power system operation and management, the large-scale generating plants are developed and controlled centrally by a single entity [2]. Indeed, co-existence of DG and this centralized power system will be interesting to be discussed, as the role of DG can reduce carbon emissions and enhancing energy security and affordability. In this decade, DG is being widely promoted by countries across the globe [3]. As the result, an increasing number of DG connected to power system were identified in developed countries such as Germany, Denmark, United States, United Kingdom, etc., [4]. The DG includes the micro-generators (either diesel or renewable energy such as residential solar PV (ground-based or rooftop), fuel cell, etc.), energy storage (heat pump), flexible demands and electric vehicle [5]. By having more DG in the system, traditional energy consumers may transform into prosumers, by participating in the market both as electricity generator and electricity consumer.

Since the DG can reduce the electricity bills and contribute to the energy transition, the uptake of distributed energy in whole power system seems uptrend in future. However, no alignment between the existing mechanisms for incentivizing distributed energy technologies and the costs and benefits analysis [6]. As an effort to follow this energy transition, the regulatory frameworks in many countries are trying to catch-up with technology options and shifting energy user's demand [1]. Issues of the renewable-based DG such unpredictability and intermittency are solved by the existence of energy storage and control devices. As all types of energy storage are predicted to be halved by 2030 [7], the energy storage also adds the ability for the consumers that produce their own electricity by DG (called as prosumers), to store their excess electricity and to utilise it by themselves or to supply to its neighbours who are in energy deficit and sell it at the right time (without utility involvement in transaction). This type of energy trading is then called as peer-to-peer (P2P) energy trading [4].

Even $\mathrm{P} 2 \mathrm{P}$ is a new concept, the studies of $\mathrm{P} 2 \mathrm{P}$ were emerged significantly due to high interest of the world to revolutionize the power market system towards the energy transition. In Ref. [4], the P2P mechanism were piloted in many developed countries. By these pilots, the study compares many P2P projects and found that some of the projects share similarities, while others may have different purposes. Many of these trails designed business models and marketplace for P2P energy trading but ignore a possibility of local energy markets. In addition, a study [8] reviewed the $\mathrm{P} 2 \mathrm{P}$ mechanism by using the comparative review of business component. The one of the findings is the $\mathrm{P} 2 \mathrm{P}$ market to secure the profitability of the business above others to make the P2P electricity trading viable. Based on five business components discussed by that study, $\mathrm{P} 2 \mathrm{P}$ types are varied in each promotion. The paper is also expected that the technological development of energy storage devices will play a major role. However, those studies did not consider detailed analysis on economic and technical components.

To address the economic potential of the P2P market, Anubhav studied 300 residential customers in the Ausgrid by metering the gross consumption and gross generation data. In his result, higher PV penetration rates result to greater supply in the P2P market, thereby pushing electricity prices down and significantly reducing the amount of electricity purchased by participants from the retailer. There is an effect of retailer revenue and distribution network operator revenue due to P2P mechanism. Supply and demand balance also affect the P2P pricing market [6]. In Alberta, a study by Leberer runs a model to simulate PV production and the settlement of P2P trades, where the results show that the import of electricity for the neighbourhood can be reduced significantly by allowing P2P trading. In addition, the paper identified that the share of solar PV uses up to $40 \%$ of residential houses, does not pose a problem for the system [9]. However, both papers were carried out in the open market, while no study yet mentioned about an adoption of the P2P mechanism for the regulated market. 
In technical perspective, P2P can be considered as one of the smart grid mechanisms [10], where this new electricity trading can be proposed at the level of participants (house to house), microgrid, among microgrids or even national [11]. To analyse the $\mathrm{P} 2 \mathrm{P}$ market, a game theory is a good approach to create the market rules and stakeholder roles [12]. The objective function and constraint for the P2P market role discussed in Nguyen's paper [13]. In P2P electricity trading, it was identified that P2P has at least four dimensional layers namely: Business layer, power grid layer, communication layer and control layer [14]. In power grid layer, a paper has also discussed detail mechanism for the communication layer and its process algorithm [10]. For each trading algorithm, it is compiled in detail by some studies [1519]. Among the advanced technology, blockchain is the common technology for supporting P2P. The basic knowledge and transaction algorithm of the blockchain are well explained in a study [17]. However, in future, some technologies such as block lattice or others are possible to be adapted in the current development due to limitation, scalability issues, etc., [20]. This study will not focus on technology and assumes that $\mathrm{P} 2 \mathrm{P}$ is technically feasible from previous studies mentioned in this paragraph.

This paper's objective is to find an alternative way on how country can keep on their way to renewable energy target with a balance of economic purposes. This alternative is by proposing a P2P market, which is generally defined as the distributed systems that enable sharing of resources across a peer population [21]. P2P recently emerges in deregulated market, yet there is no applicability of $\mathrm{P} 2 \mathrm{P}$ in regulated market to date. This study was finished in June 2019, while P2P energy trading pilot run in Malaysia commenced in November 2019-June 2020. In regulated market, a single buyer or single seller utility model applies. This entity is responsible for the upstream (generation) and downstream (distribution/retail) of the electricity business. Even, now the competitions in generation side emerges to relieve the investment burden by inviting privates to market, however, the main grid is solely owned by the same power utility to ensure its role as the only supply for consumers.

This study aims to investigate the implementation of $\mathrm{P} 2 \mathrm{P}$ in regulated market, where there is an application of net metering/billing. Net Metering and Net Billing are the policies that allow residential solar PV prosumers to sell its excess electricity to the utility grid, with a certain price. In net metering, a transaction is calculated based on a net of $\mathrm{kWh}$ consumption minus its $\mathrm{kWh}$ productions (single metering). Differently, a transaction of net billing is done separately where it is calculated based on the net of total consumption billing minus total production billing. An institutional design of P2P concept for the regulated market is also proposed through this paper. Through those objectives, the paper will respond to this question on 1) how a regulated-electricity business in a country can prepare the P2P market without unbundling the market entirely in economic perspective, 2) how cost benefit analysis investigated in P2P market. Indeed, P2P will ensure the continuation of country efforts to accelerate the renewable energy development.

To address the objectives and questions, this paper is structured as follow: Section 2 briefly introduces a recent problem on renewable energy mechanism for residential solar PV use, while further it will mention about the differences between the existing mechanism and peer-to-peer in regulated market. A structure of P2P in the vertically integrated unit market is then also depicted with four types of participants: Producer with storage system (type A), producer without storage system (type B), pure consumer (type C) and consumer with only storage system (type D). Section 3 discussed on the P2P market arrangement, cost-benefit methodology, and economic analysis with their general assumptions. This will entail a proposed $\mathrm{P} 2 \mathrm{P}$ system for regulated market and will identify the uniqueness from existing P2P mechanisms. The findings of the economic analysis and cost benefits analysis for the regulated market are discussed in Section 4. At the end, Section 5 gathers the conclusions and suggests the future works. 


\section{PROBLEMS AND SOLUTIONS ON RENEWABLES TRADING MECHANISM}

\subsection{Problem on Energy Trading Mechanism}

At present, the most of regulated countries implemented the feed-in-tariff (FIT) to encourage the market to be well established. The FIT market has been the most common and effective tool in the development of variable renewable energy generators [22]. Yet, some countries have already been saturated with the FIT as it is an artificial market where the national budgets are used to pay higher electricity prices from renewable energy developers. As the result, FIT is now seen as less attractive policy for the developers where the additional subsidy decreased year-by-year [6,23]. Purchasing the renewable-based electricity at higher price will hinder relevant utilities to serve their electricity at affordable price in regulated tariff.

As alternative, some countries apply net metering (NM) or net billing which instead offers the benefits through next month savings for all prosumers. However, the price is not fairly compared 1:1, where excess electricity is less valuable than grid electricity price. Indonesia, Philippines and Thailand imposed the price below the retail one. Net metering is worsened if any expiration period applies (such as Indonesia: three months) or year-operation limit (such as Thailand: 10 years). Indeed, these will affect to economic benefits of each developer and discourage the development of solar PV uses. Therefore, a $\mathrm{P} 2 \mathrm{P}$ is proposed as an alternative of this issue.

\subsection{The Existence of Peer-to-Peer Mechanism}

As defined earlier, P2P is applied for many application domains, including the electricity trading [24]. In 1999, Nepster was established as the music and file sharing application, as precursor of P2P system [25]. Through a client-sharing model, the P2P can encourage participating users to establish a virtual network entirely independent from physical network, without having to obey any administrative authorities or restrictions [26] This concept is then adapted into economy such as Airbnb, in 2008 [27], this system is being implemented as a real energy business type before many pilot projects such as: Piclo, Vandebron, Yeloha, Sonnen Community, Microgrid Sandbox, etc, followed after Ref. [8]. In energy business, the scope of $\mathrm{P} 2 \mathrm{P}$ markets was recently introduced in the distribution networks.

P2P energy trading, also referred to as virtual NM, is an incentive mechanism under which the exported generation of distributed customers are traded on a time-of-use basis with other local customers [6]. This enables consumers to become prosumers by selling their surplus energy from their renewable resources and storage to their neighbourhood. P2P energy trading thus empowers prosumers to trade renewable energy beyond geographic boundaries [13]. The P2P involves novel technologies and business models at the demand-side of power systems, which can manage the increasing connection of DG, where prosumers directly trade energy with each other to achieve a win-win outcome [28].

\subsection{Main Differences between Centralised System-based Mechanisms and Peer-to-Peer Mechanism}

In conventional electricity business, the development of high voltage transmission line and large substations are common to transfer the electricity from the generators to the consumers in such distances [29]. Long term demand forecast is also an issue of overbuilt infrastructure, where this may waste the money and leads to higher price electricity or burdening the power utility in capital cost and amount of loans. In contrast, P2P market has a unique characteristic where the market will not encounter those issues as it is without any centralized agent as well as requires the simultaneous negotiations over the energy transfer and prices [19]. It is more transparent in term of clearing mechanism, since the P2P cannot be applied without a software platform [15] and allowing an immediate, automated and flexible energy transactions based on market rule: Supply and demand balance [29]. Fig. 1 explained the differences between conventional centralised model, centralised with NM system and centralised with $\mathrm{P} 2 \mathrm{P}$ market in the regulated market with single buyer entity. 


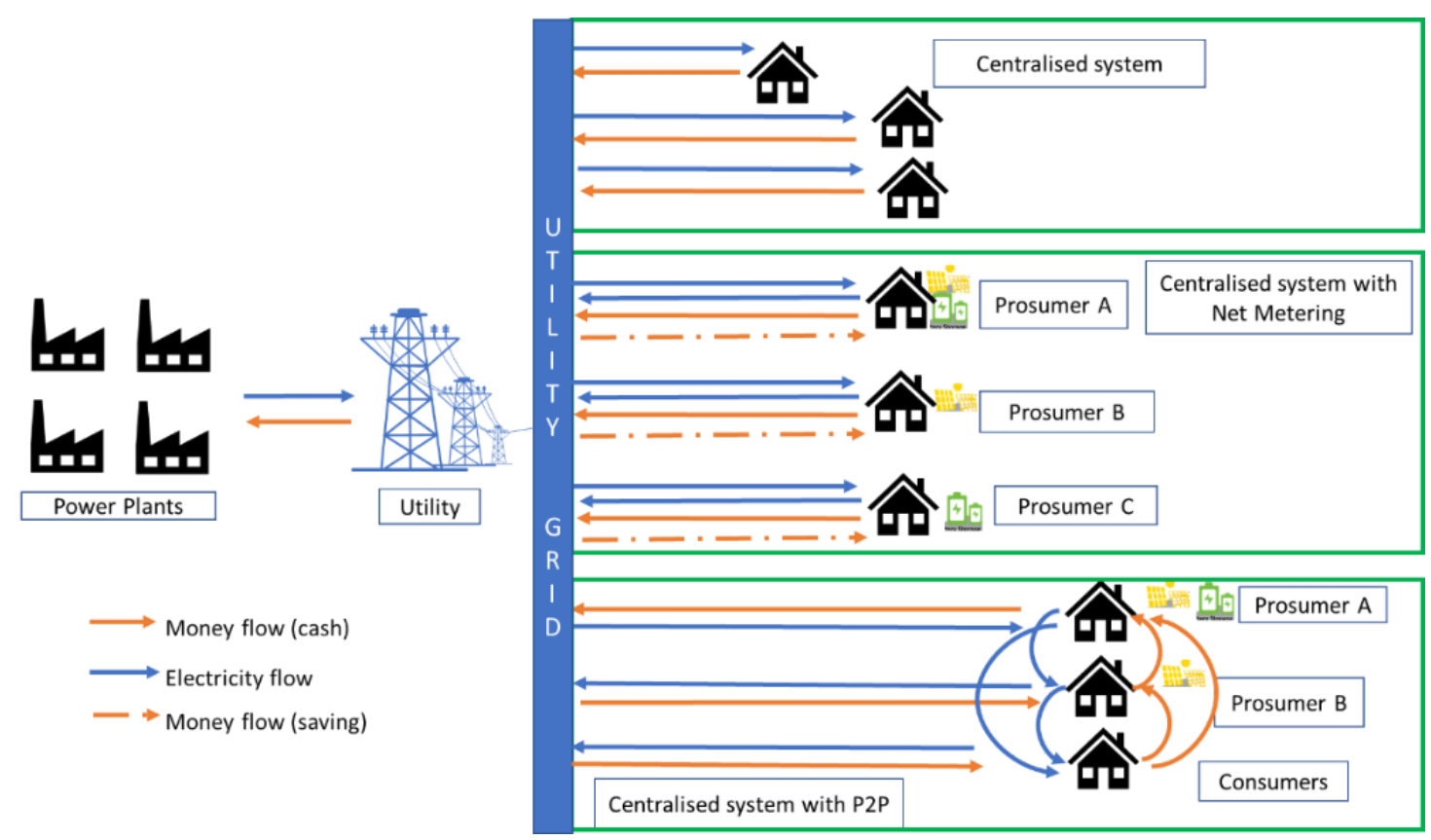

Figure 1.Conventional power system without any mechanism, with net metering/billing mechanism and with $P 2 P$ market models [developed by authors]

\section{METHODOLOGY}

Mostly peer-to-peer (P2P) was introduced in the deregulated electricity market countries, such as UK, Australia, etc. Based on Ref. [11], four main layers are identified in the P2P electricity trade: Control, technology (ICT), transaction (business) and power grid layers. These four layers are dependent on the three variables, complexity, time, and the capacity of participants: Either could be in household level, industrial level, microgrid level, or even subnational and national level. Power grid layer represents all physical components in the power system, including the loads, feeders, transformers, smart meters, generators, etc. Technology represents the databanks, the communication devices, protocols, applications, and information flow. Control mainly includes the automatization control and other functions related to the flow of electricity in distribution system to ensure the grid is in appropriate condition. Transaction layer will include the databanks of transaction, the way of transaction, the rules of game, who are involved and what are their roles. The regulation of trading is included in this layer. In this section, the identification of these layers in regulated market will be proposed. The following introduction on how the technology and market arrangements are necessary prior to market design.

\subsection{Technology Arrangement for P2P Market}

In communication layers, an advanced technology is necessary to be attached in the market to ensure the transparency and reliability of the transaction. A blockchain is the common technology for supporting P2P where basic knowledge and transaction algorithm of the blockchain are well explained in [17]. Under Ref. [9], blockchain is well implemented in some countries including Australia, where this technology enables consumers to sell electricity to peers. In case of Powerledger - an Australiabased company, blockchain allows the settlement of hundreds of thousands of trades in the five-minute settlement intervals without a centralized third-party taking control of the required data, establishing trust and charging fees resulting in the creation of bureaucracy.

In physical units, a smart meter - an electronic meter will measure a lot of parameters including instantaneous power, energy consumption over time, power factor, reactive power, voltage, and frequency with high accuracy. To measure all the transactions on time and precisely, Ref. [11] proposed 
to use the electronic smart meter in $\mathrm{P} 2 \mathrm{P}$, where they are interconnected each other under the communication platform, namely as the home area network. In P2P, each transaction will be accounted through the smart meter, where the detail process of transaction will be discussed later. A smart meter and blockchain shall be integrated in term of data process, from data management, acquisition, validation, storage, adjustment, and calculation. In term of communication flow, Ref. [11] identified three communication area, started from home area network, to neighbourhood to wide area network. This paper only discusses the economic potential of combinations between peers in neighbourhood system.

\subsection{General Market Arrangement for P2P Market}

In general case, there are minimum four peer's types (participant) in $\mathrm{P} 2 \mathrm{P}$ market. They are producer with storage system (type A), producer without storage system (type B), pure consumer (type C) and consumer with only storage system (type D), as identified in [13]. This study will only limit the DG is sourced from the solar PV, while the energy storage is solely considering the batteries. Therefore, the authors consider a $\mathrm{P} 2 \mathrm{P}$ population $(\mathrm{P})$ consist of a set A type, B type, C type and D type participants (described below) as formulated in Eq. 1.

A type: Set of households with a solar PV system and an energy storage installed

B type: Set of households with only a solar PV system installed

C type: Set of households without a solar PV system and an energy storage

D type: Set of households with a storage system, without the solar PV system

$$
P=\{A \cup B \cup C \cup D\}\}
$$

After a P2P population is defined for the regulated market, the possible actions of each set of participants are determined to help the aggregator understand the flow of electricity and transaction (see Fig. 2).

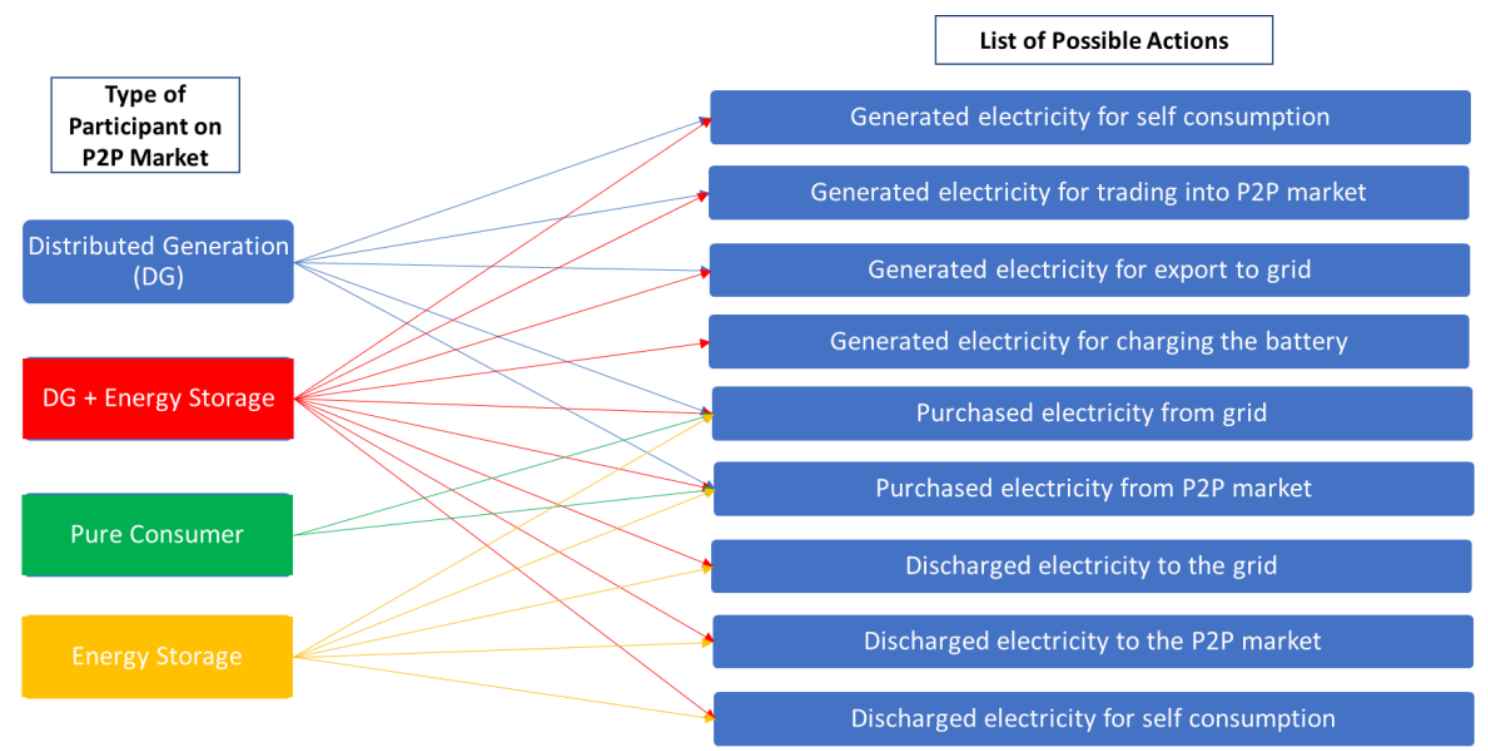

Figure 2. Each participant's role in P2P market with main grid connection.

To identify the market model is the next thing in designing P2P market. In general context, P2P communication model was proposed with four alternative models: 1) Unstructured centralised model, 2) unstructured decentralised model, 3) hybrid model and 4) structured decentralised model as presented in Fig. 3 [30]. Either structured or unstructured and decentralised or centralised can have the types of participant discussed in Eq. 1. Based on those participants, the P2P electricity trade market model can be set at four communication and transaction model. The concept is similar to three identified structures introduced by Tiago Sousa: full P2P structure, community-based structure and Hybrid (nested) structure. 

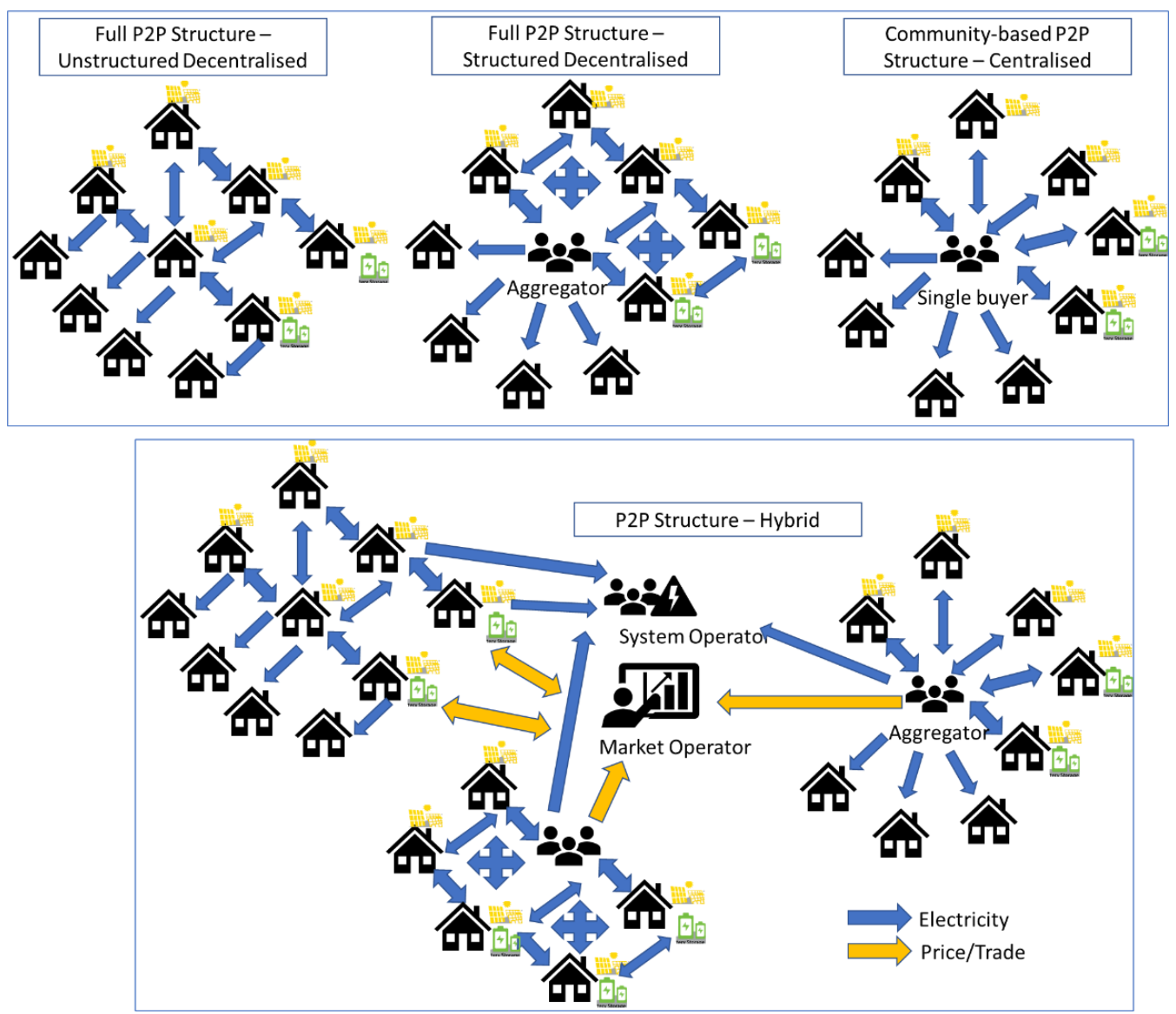

Figure 3. Four general types of market model for P2P

\subsection{Specific Market Arrangement for P2P Market in Regulated Market}

This study will specifically take an example of a developing country with single buyer market (vertically integrated market). In this regard, the consumer with energy storage seems rarely possible for the developing country. Therefore, the population of regulated market will only be represented by prosumer with energy storage (A), prosumer without energy storage (B) and consumer without storage (C). Beside economic perspective, consumers in this market are always connected with $24 / 7$ system, therefore the consumer with battery only is more possible in rural area.

This study will only limit DG with solar PV only. Diesel generator is not counted as it has huge emissions during its operation, while this study is only focusing on renewable energy. However, the small scale of wind for residential is not economically viable yet even with the FIT (8-9 cent $€ / \mathrm{kWh}$ ) [31], therefore solar PV is solely considered as a technology used in this model due to its prominence use in residential sector.

In the regulated market, a single-buyer utility will take a role as an aggregator. This is either joint venture with privates or standalone subsidiaries of single buyer utility. The difference between this and structured decentralised is on utility function, where it manages the electricity flown from one household to another. Such net metering, the electricity run through the utility grid, but then transaction is considered between one house to other houses (not to the utility). Other two fundamental differences are the pricing system and the market availability. The pricing mechanism (discussed later) is determined by the electricity supply and demand balance in P2P community only. Even regulated market will determine the tariff, a policy can be enacted by adopting this study's tariff formula for P2P market. As long as the formula is consistent and regulated, P2P is possible to be run in the regulated market. 
In P2P, an aggregator will also be known as community manager. Its function is to supervising the energy trades, interacts with other managers (if any) and grid operator (which is another subsidiary of single buyer utility or the utility), and monitor the electricity balance transfer in and out of the main grid. The aggregator shall promote all the members or P2P market participants to install their special metering which is integrated and interlinked each participant and to aggregator. All electricity enters to and exits from the P2P market are then metered in each meter and single buyer has a sharing meter, where summarise and conclude the balance with the main grid. Therefore, the concept of community-based P2P structure is preferable for regulated market (illustrated by Fig. 4) where single buyer can control the market and it will not disobedient single-buyer law.

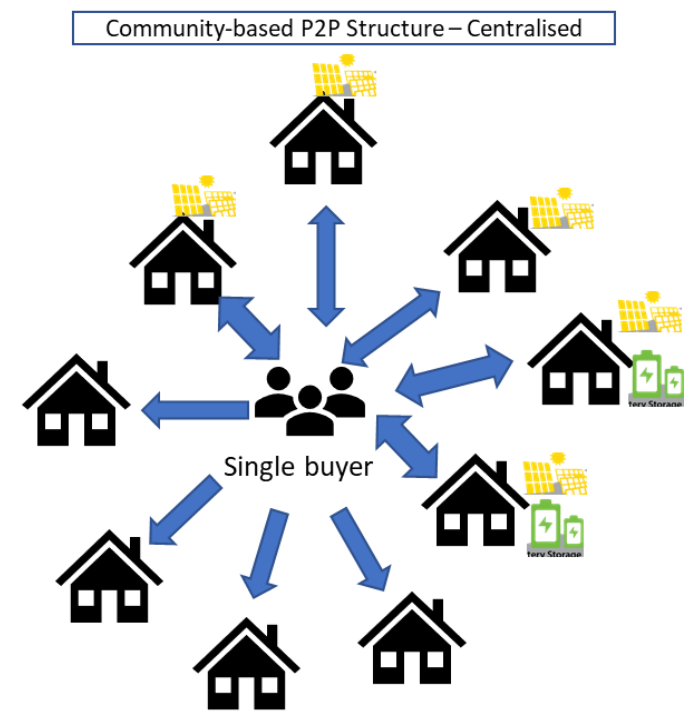

Figure 4. Four general types of market model for P2P

To simplify the calculations, authors categorised all the participants of $\mathrm{P} 2 \mathrm{P}$ into six models of load profile that usually common for residential sector in the developing country based on the current activity of households and weekend/weekdays. The activity-based profiles are morning/evening peak (common workday), stay at home (in case of holiday), work at night (nocturnal workday). Three of them will be different during weekdays and weekend/holidays profile. During holidays/weekend, residential demand is expected to be higher than the weekdays (assumed to be 20\% higher), while average demand during the weekdays in population of country selected for this study is at $17 \mathrm{kWh}$ per day. It is assumed that each household may have different load profile characteristic in weekend and weekday, or it could be same. For a year, the holidays in the developing country is assumed at 22 days per month. In this study, an example of solar irradiation profile referred to [32] is considered in this analysis with detail varieties of load profile are presented in ANNEX 1.

Under the P2P market, there are three process for electricity transaction $[6,14,33]$. The transaction is started by Bidding Process as the first process of trading when energy users (generators, consumers and prosumers) signing contracts with each other prior to the real-time energy exchange. The Period of Exchanging is the second process in which energy is generated, transmitted and consumed by users. As the final process, the bills and transactions are finally settled via various payment methods called as the Period of Settlement. The electronic meters shall accommodate those process in P2P market. Ideally, two types of pricing namely reservation purchase price and sales price between the seller and the buyer are considered as the selling and buying [6,34].

$R_{p p}(i, t):$ reservation purchase price $(\$ / k W h)$ in time slot $t$ for each household $i$.
$R_{s p}(i, t)$ : reservation sale price $(\$ / k W h)$ in time slot t for each household $i$

Considering that the objective of this paper is to investigate $\mathrm{P} 2 \mathrm{P}$ in regulated market which net metering is less or more than the retail electricity $\operatorname{cost}\left(\mathrm{NM}<\mathrm{c}_{\mathrm{e}}\right)$, this study proposes the purchase and sales pricing 
mechanism as presented in Eqs. 2,3. The price will be applied for 1 day and equal to every household, depending on total available customer and prosumer at that day.

$$
\begin{gathered}
R p p=c_{e} \times\left(N M+\left(\left(\frac{c_{e}-N M}{c_{e}}\right) \times\left(1-\frac{1}{a}^{\frac{n_{c}}{n_{p}}}\right)\right)\right) \text { where } N M / c_{e}<1 \\
R s p=c_{e} \times\left(N M+\left(\left(\frac{c_{e}-N M}{c_{e}}\right) \times\left(\frac{1}{a}^{\frac{n_{c}}{n_{p}}}\right)\right)\right) \text { where } N M / c_{e}<1
\end{gathered}
$$

where, NM denotes net metering price (US\$ $/ \mathrm{kWh}$ ), this study proposes to set $65 \%$ of retail price. This is approached by net metering regulation in Indonesia, which electricity sold by prosumers are only compensated at $65 \%$ of the retail electricity price. Some countries set it out lower, and some countries higher.

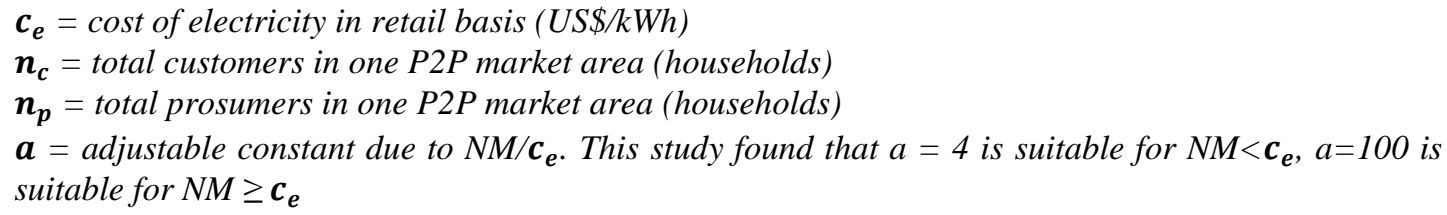

\subsection{Objective Function and Parameters for P2P Economic Analysis}

The objective function is to create the optimal results on the cost-benefit analysis, where it would be lowest payback period (see Eq. 4), highest net present value or NPV (see Eq. 5), and internal rate of return or IRR (see Eq. 6)

$$
\begin{gathered}
\text { Minimize Payback Period } \mathrm{PP}=\frac{\mathrm{I}}{\left(\mathrm{r}_{\mathrm{n}}-\mathrm{c}_{\mathrm{n}}\right)} \text { where }-\mathrm{I}+\sum_{\mathrm{n}=0}^{\mathrm{N}}\left[\mathrm{C}_{\mathrm{f}}\right]=0 \\
\text { Maximize Net Present Value } N P V=-I+\frac{\sum_{n=0}^{N}\left[C_{f}\right]}{(1+i)^{n}} \\
\text { Maximize IRR (i) where } N P V=-I+\frac{\sum_{n=0}^{N}\left[C_{f}\right]}{(1+i)^{n}}=0
\end{gathered}
$$

where,

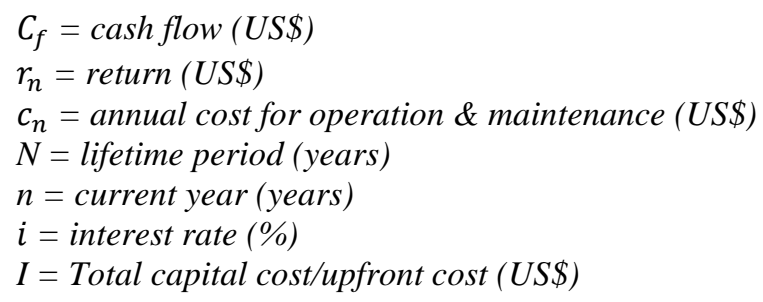

Based on Ref. [35], an NPV method is one of economic method with most effective and accurate technique based on most modern books and courses in comparison to payback period, ROI and IRR [36]. In this model, the NPV is a method to assess the profitability of residential solar PV projects as 
well as to measure on how the economic value in each participant. Payback period is solely to figure on how the project is feasible in simple way.

To consider on how much the electricity cost for each prosumer, the Levelized Cost of Electricity (LCOE) is defined in this paper. The LCOE is representing the net present value of the unit-cost of electricity over the lifetime of a generating asset. The levelized cost is that value for which an equalvalued fixed revenue delivered over the life of the asset's generating profile would cause the project to break even. This can be roughly calculated as the net present value of all costs over the lifetime of the asset divided by the total electricity output of the asset. In estimating the LCOE used the formula seen in Eq. 7 [37]:

$$
L C O E=\frac{\sum_{n=0}^{N} \frac{\left[C_{n}\right]}{(1+i)^{n}}}{\sum_{n=0}^{N} \frac{\left[P_{n}\right]}{(1+i)^{n}}}
$$

where,

$$
\begin{aligned}
& C_{n}=\text { Total Cost }(\text { US } \$) \\
& P_{n}=\text { Power Generation }(\mathrm{kWh}) \\
& N=\text { lifetime period }(\text { years) } \\
& n=\text { current year }(\text { years }) \\
& i=\text { interest rate }(\%)
\end{aligned}
$$

For P2P participants, total costs cover three cost components. Firstly, investment cost is the upfront cost for prosumers to install their residential-based solar PV or plus storage cost. This include solar PV module, mounting/structure, inverters, cables and administration costs to install and properly connect with P2P grid. Secondly, the operation and maintenance cost will cover the cost to operate and maintain the system if any imbalance or disturbance. This also consider any replacement costs required for battery and inverters in 20-25 years operational lifetime. Thirdly, a P2P grid management cost is a subscription for P2P metering or membership to the community that covers all tools needed in their household and the management service from aggregator (utility in regulated market context).

\subsection{Cost benefit analysis for the utilities}

This study also identifies how much the cost-benefits for utility if the P2P market will be established in their market. The selected case study proposes an establishment of P2P in a developing country with the regulated market. This assumes that the regulated market can allow the direct electricity trading between each household through the utility, but the utility has less than $1 \mathrm{GW}$ solar PV installed yet. As the utility in nascent of solar PV development, distribution line is also assumed to be limited by a certain level of solar PV penetration. This study suggests the penetration limit is up to $20 \%$ of total peak demand in a single relay station. However, this study will initiate the use of 5\% solar PV penetration of peak demand range in $3,540 \mathrm{~kW}$ to $7,533 \mathrm{~kW}$ in a day (depends on the load assumptions) from 6,378 households in a single feeder [38].

The retail price of electricity is approximated by Indonesia's electricity retail price at 10 cent US\$/kWh comprising the existing margin plus administrative cost for utility and the tax assumptions at $22 \%$ and $10 \%$ of retail price, respectively. National electricity production cost is averagely assumed at 7.8 cent US $\$ / \mathrm{kWh}$. This assumption is approached by average production cost in large and mature system in Indonesia. Due to various technology and demand characteristics, each nation can have different numbers. 
The cost benefit analysis will only cover the following calculations:

1) The provision of power wheeling charge $(+$, tangible $)$

2) The net revenue of selling charge for smart meter (+, tangible)

3) The monthly subscription of the P2P customers for smart meter of which include mandays of laymen to operate the system and technology cost. This can be stated as wheeling charge benefits $(+$, tangible)

4) The avoided cost to invest on solar PV/purchasing electricity through existing feed-in tariff mechanism due to consumer-based investment for solar PV $(+$, intangible)

5) The loss of electricity selling due to the P2P market trading (-, tangible)

The avoided cost (point 4) is an investment saving that can be made by the utility just in case of the renewable energy development is centralised from government funding to utility. The P2P market will remove this investment requirement from government to the consumers who will install their solar PV for P2P market. Thus, the utility will not need to spend any penny of national budget to build the exact same installed capacity of solar PV. Moreover, above notes will have a sign (+) for any utility possible income, otherwise the expense will be signed as (-).

Later in Section 4, the results and discussion for $R_{s p}$ and $R_{p p}$ will be applied to the selected P2P population determined in this study. In this population, the P2P participants are 159 of 6,378 households assumed with capacity $1,300 \mathrm{kVA}$. This is assumed by capacity grouping in Indonesia. $1300 \mathrm{VA}$ is predominant in Indonesia. The solar PV installation of each household are considered at 1.17 $\mathrm{kWp} /$ household averagely. The total installed solar PV will be calculated based on Eq. 8.

$$
P_{P 2 P}=P_{\text {peer }} \times n_{\text {prosumer }}
$$

$P_{P 2 P}=$ Installed solar $P V$ in whole pilot project system $(k W p)$.

$P_{\text {peer }}=$ Installed solar PV in each household, where it is $90 \%$ of maximum household demand capacity.

$n_{\text {prosumer }}=$ Total prosumer in P2P market, where Peer Type A (111 households) and Peer Type B (8 households).

Total installation cost for PV is assumed as 8.5 cent US $\$ / \mathrm{kWp}$ (all includes, except battery), similar to what paid by P2P participants. This will be applied to utility saving to not invest in solar PV or purchase electricity through feed-in-tariff or other existing mechanisms (possible to be higher than solar PV installation costs).

\subsection{Ideal Condition}

The ideal condition is defined where the household only has one option to sell its electricity through NM only. To compare with P2P market analysis, the ideal condition is defined as Table 1. Next, it will compare with other load profiles. The analysis will show the results of comparison between NM mechanism and $\mathrm{P} 2 \mathrm{P}$ mechanism.

This study proposes that there are at least 6 combinations of load profiles from many various types of demand characteristics (see

Table 2). These combinations are formulated from two types of day between the weekdays and the holiday/weekend and three types of activity-based load profiles, which are morning/evening peak (common workday), stay at home (in case of holiday), work at night (nocturnal workday). These following load types are assumed as a common approach of loads based on authors' observations in urban area of developing countries such as Indonesia, Thailand and Malaysia. These countries were considered as per this study's suggestion to explore a P2P community in Jakarta area, Indonesia. 
Table 1. Ideal condition for each household.

\begin{tabular}{lll}
\hline \multicolumn{1}{c}{ Parameters } & \multicolumn{1}{c}{ Nominal } & \multicolumn{1}{c}{ Unit } \\
\hline Average electricity used in weekdays & 17 & $\mathrm{kWh}$ \\
Average electricity used in weekends/ holidays & 21 & $\mathrm{kWh}$ \\
Installed Solar PV & 2,475 & $\mathrm{Wp}$ \\
Battery Capacity & 2,400 & $\mathrm{Vah}$ \\
Amount of Battery (parallel x series) & $4 \times 1$ & $\mathrm{Unit}$ \\
Solar PV Installation Cost & 850 & $\mathrm{US} \$ / \mathrm{kWp}$ \\
Inverter Cost & 282 & $\mathrm{US} \$ / \mathrm{kWp}$ \\
Battery Cost & 148.71 & $\mathrm{US} \$ / \mathrm{kWh}$ \\
Lifetime for Solar PV & 20 & Year \\
Lifetime for Inverter & 10 & Year \\
Lifetime for Battery & 5 & Year \\
Discount Rate & $6 \%$ & Not available \\
Economic Period & 10 & Year \\
Load Profile in Weekdays & Morning/evening peak & \\
Load Profile in Weekends/ Holidays & Stay at home & \\
\hline
\end{tabular}

Table 2. Definition on Different Types of Load

\begin{tabular}{lll}
\hline Type of Load & \multicolumn{1}{c}{ Weekdays } & \multicolumn{1}{c}{ Weekend } \\
\hline Load Type 1 & morning/evening peak & stay at home \\
Load Type 2 & stay at home & stay at home \\
Load Type 3 & nocturnal & nocturnal \\
Load Type 4 & nocturnal & stay at home \\
Load Type 5 & morning/evening peak & morning/evening peak \\
Load Type 6 & morning/evening peak & nocturnal \\
\hline
\end{tabular}

\section{RESULTS AND DISCUSSIONS ON P2P COST-BENEFIT ANALYSIS}

The cost benefits analysis is applied to identify the benefits for participant and for the utility.

\subsection{Benefits for Participants.}

As the results, all model shows that using P2P mechanism may benefit the prosumers through an economic analysis such as the internal rate of return and the payback period. As prosumer without the energy storage (solar only), the participants will cost higher than through NM, due to the smart metering purchase. Based on

Table 2, the load types were analysed by taking six economic parameters into account. The six parameters are annual benefit, annual cost, payback period, LCOE, IRR and NPV. Table 3 encompassed the results of economic analysis for various type of load determined for this study.

Table 3. Economic analysis for NM and P2P in 6 common load profiles.

\begin{tabular}{|c|c|c|c|c|c|c|c|c|c|}
\hline \multirow[b]{3}{*}{ Economic Parameter } & \multirow[b]{3}{*}{ Unit } & \multicolumn{4}{|c|}{ Load Type 1} & \multicolumn{4}{|c|}{ Load Type 2} \\
\hline & & \multicolumn{2}{|c|}{ Solar Only } & \multicolumn{2}{|c|}{ Solar+Battery } & \multicolumn{2}{|c|}{ Solar Only } & \multicolumn{2}{|c|}{ Solar+Battery } \\
\hline & & NM & $\mathrm{P} 2 \mathrm{P}$ & NM & $\mathrm{P} 2 \mathrm{P}$ & NM & $\mathrm{P} 2 \mathrm{P}$ & NM & $\mathrm{P} 2 \mathrm{P}$ \\
\hline Annual benefit & US\$/yr & 265 & 304 & 354.1 & 449 & 285 & 319 & 379.5 & 440 \\
\hline Annual Cost* & US\$/yr & 24.7 & 25 & 218.6 & 219 & 24.7 & 25 & 218.6 & 219 \\
\hline Payback period (replacement) & Yr & 9.9 & 8.8 & 15.9 & 12.5 & 9.2 & 8.4 & 14.8 & 12.8 \\
\hline LCOE & $\mathrm{c} / \mathrm{kWh}$ & 8.6 & 8.9 & 18.0 & 13.5 & 8.9 & 9.2 & 17.2 & 14.1 \\
\hline IRR & & $10.1 \%$ & $11.3 \%$ & $3.6 \%$ & $5.9 \%$ & $10.9 \%$ & $11.9 \%$ & $4.2 \%$ & $5.7 \%$ \\
\hline NPV & US\$ & -611.22 & -411.76 & -2805.8 & -768.02 & -468.61 & -300.12 & -2617.9 & -839.42 \\
\hline Economic Parameter & Unit & \multicolumn{4}{|c|}{ Load Type 3} & \multicolumn{4}{|c|}{ Load Type 4} \\
\hline Annual benefit & US\$/yr & 252 & 296 & 260.5 & 445 & 254 & 294 & 296.5 & 425 \\
\hline Annual Cost* & US\$/yr & 24.7 & 25 & 218.6 & 219 & 24.7 & 25 & 218.6 & 219 \\
\hline
\end{tabular}




\begin{tabular}{lccccccccc} 
Payback period (replacement) & $\mathrm{yr}$ & 10.5 & 9.1 & 22.2 & 12.7 & 10.4 & 9.2 & 19.3 & 13.3 \\
LCOE & $\mathrm{c} / \mathrm{kWh}$ & 8.2 & 8.5 & 23.7 & 13.9 & 8.6 & 8.9 & 21.7 & 14.2 \\
IRR & & $9.6 \%$ & $11.0 \%$ & $1.1 \%$ & $5.8 \%$ & $9.6 \%$ & $10.9 \%$ & $2.0 \%$ & $5.3 \%$ \\
NPV & US\$ & -706.2 & -465 & -3499 & -798 & -693.94 & -485.78 & -3232.6 & -946.35 \\
\multicolumn{1}{c}{ Economic Parameter } & Unit & \multicolumn{2}{c}{ Load Type 5 } \\
\hline Annual benefit & US\$yr & 268 & 310 & 348.2 & 477 & 264 & 306 & 318.2 & 469 \\
Annual Cost* & US\$yr & 24.7 & 25 & 218.6 & 219 & 24.7 & 25 & 218.6 & 219 \\
Payback period (replacement) & yr & 9.8 & 8.6 & 16.2 & 11.8 & 10.0 & 8.7 & 17.8 & 12.0 \\
LCOE & $\mathrm{c} / \mathrm{kWh}$ & 8.2 & 8.5 & 17.8 & 13.0 & 8.2 & 8.5 & 19.4 & 13.3 \\
IRR & & $10.2 \%$ & $11.6 \%$ & $3.4 \%$ & $6.6 \%$ & $10.0 \%$ & $11.4 \%$ & $2.6 \%$ & $6.4 \%$ \\
NPV & US\$ & -587.5 & -362.4 & -2849 & -565.1 & -623.43 & -391.04 & -3072.2 & -619.63 \\
\hline
\end{tabular}

In Ref. [30], a payback period and IRR cannot well represent the economic viability, therefore the analysis of its NPV then also requires in this study. Due to this calculation, no project is taking a benefit in net-present value analysis due to short economic period. The discounted annual revenue with $6 \%$ discount rate cannot recover the total upfront cost. In comparison of both participants, the NPV for prosumer without battery will be taking many benefits than the prosumer with battery (Figs. 5, 6). However, the fall of battery and solar PV prices in short future will also impact to correct this value into a positive NPV.

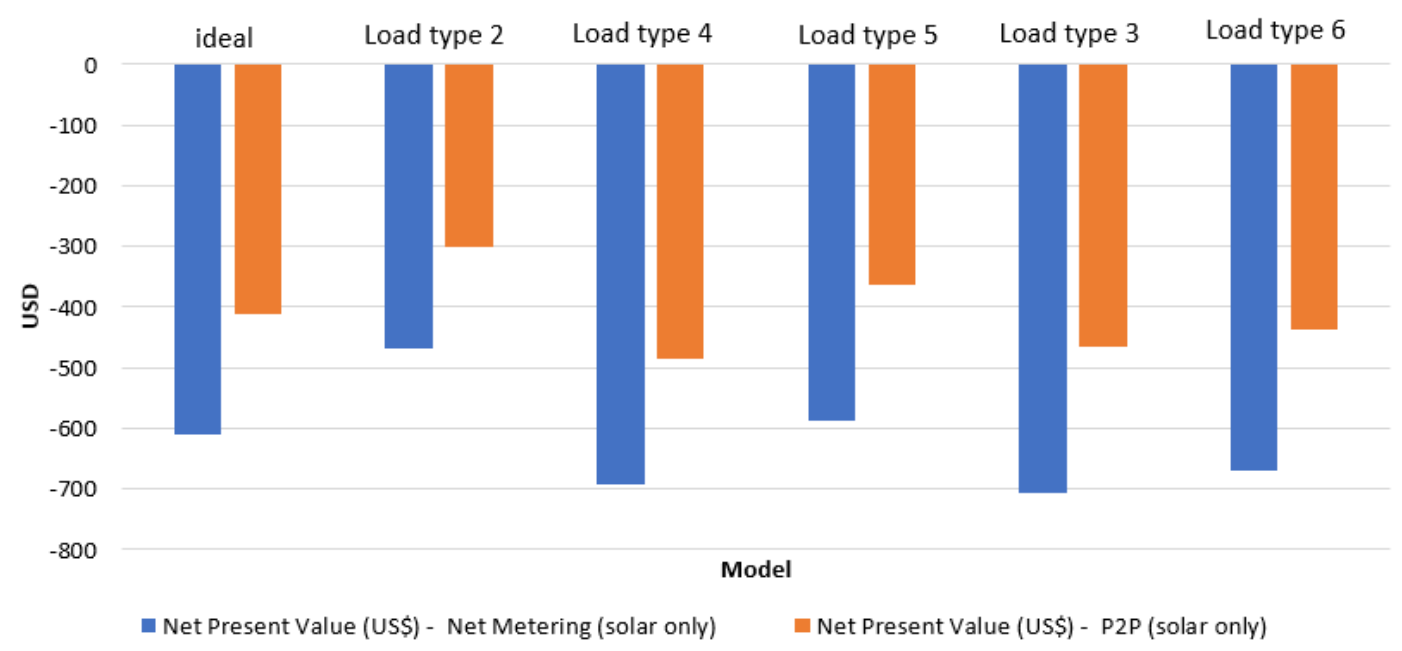

Figure 5. Net present value for prosumer without battery in P2P market.

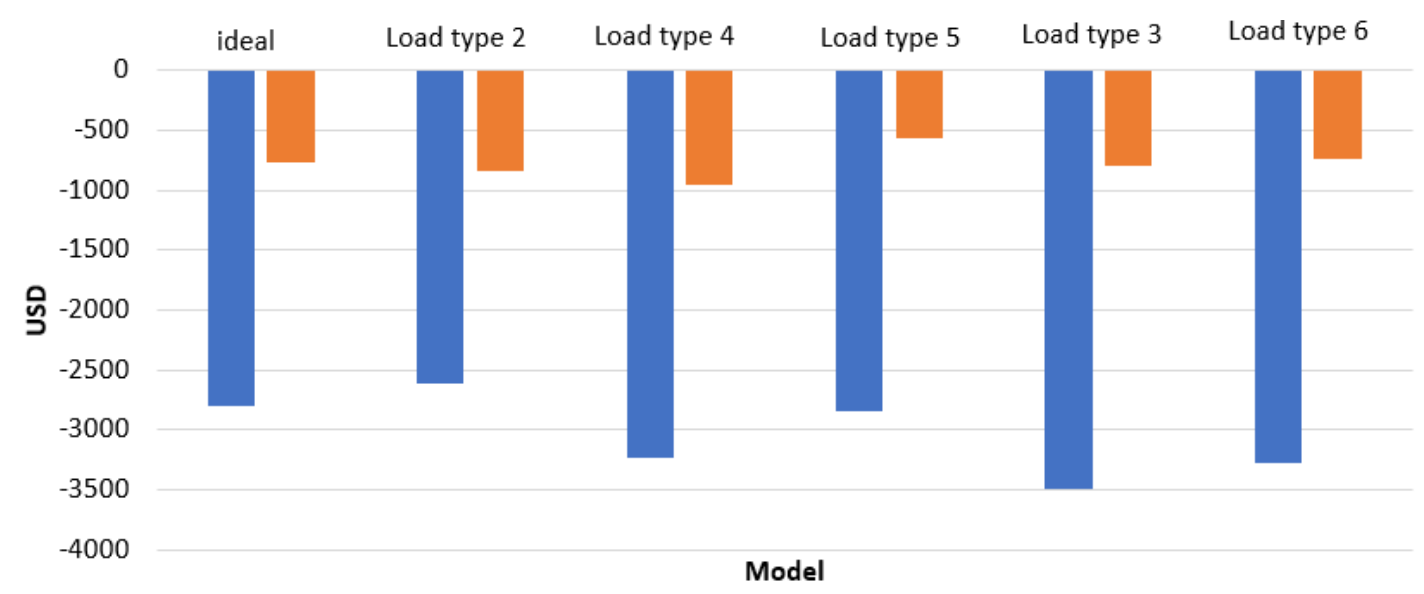

n Net Present Value (US\$) - Net Metering (solar+battery) $n$ Net Present Value (US\$) - P2P (solar+battery)

Figure 6. Net present value for prosumer with battery in P2P market. 


\subsection{Benefits for Sub-Utility}

Referring to Eqs. 2,3, the cost-benefits analysis in utility perspective will consider the RSP and RPP as presented in Table 4. The total prosumers and customers are mentioned in Section 3.5.

Table 4. Simple economic analysis of $P 2 P$ market with $R_{S P}$ and $R_{P P}$.

\begin{tabular}{lll}
\hline Parameter & Amount & Unit \\
\hline $\mathrm{R}_{\mathrm{SP}}(0,79$ of retail electricity price) & 0.080 & $\mathrm{US} \$ / \mathrm{kWh}$ \\
$\mathrm{R}_{\mathrm{PP}}(0,86$ retail electricity price) & 0.088 & $\mathrm{US} \$ / \mathrm{kWh}$ \\
Electricity trading & 2,182 & $\mathrm{US} \$ /$ year \\
Savings from Importing Utility Electricity & 1,084 & $\mathrm{US} \$ /$ year \\
\hline
\end{tabular}

Through the selected P2P community in Section 3.5, the utility is possible to grant a total revenue (tangible and intangible) of US\$ 170,213 from the P2P market (accounted with losses due to utility customer exit and select the P2P) as shown in Fig. 7. This is not much in comparison with annual revenue from a utility in whole country, but if P2P market expanded into larger units, this amount could be significantly accounted into utility's income.

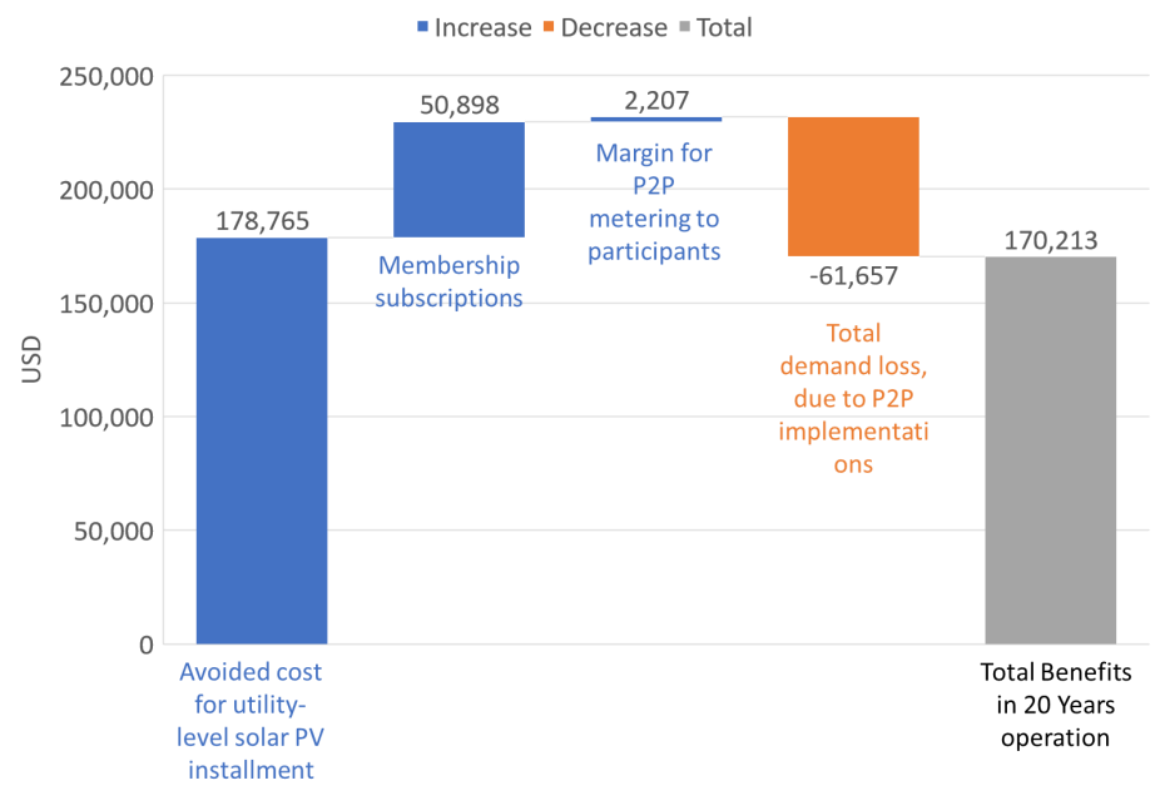

Figure 7. The Cost-benefits analysis for P2P market in selected area in single buyer regulated market

\section{CONCLUSIONS}

The plunge of solar PV and energy storage prices are good momentum for the consumer to be prosumer in near future. Their excess electricity enables households supply each other instead of purchasing electricity from utility grid, compensates other whose energy deficit. The utility of single buyer shall create the sub-utility who will in charge to manage and rule the P2P trading with more transparency on the price and daily based market price.

Through this study, P2P was found more economically feasible than net metering for both utility and residential participants. In comparison with current net metering, solar photovoltaic (solar PV) installer can fasten their payback period up to 2 years from its net metering payback, raise internal rate of return (IRR) by $2-3 \%$, obtain more 500 US $\$$ net present value (NPV) for prosumer only (a consumer with electricity generator such as solar PV) and 3,000 US\$ for prosumer with storage system. In utility 
perspective, utility can explore all the cost benefits from their roles as aggregator. Though, utility lost its demand, somehow the participants still require utility in the time that market cannot provide enough supply. Moreover, they can save more than US\$170,213 as their benefits after compensating all costs they need to pay or loss they need to suffer. This shows that P2P market has advantages for regulated market, economically. In proposed arrangement (Section 3), a country whose consecutive law does not allow any transaction other than the utility is institutionally feasible to run P2P market practically with the utility as an aggregator. However, further legal basis study is required.

There is no evidence analysis on how $\mathrm{P} 2 \mathrm{P}$ can also release the fiscal burden of government in achieving their renewable energy target. However, if utility can save their investment, it means government will reduce its financial assistances to pay electricity from renewable IPP. In another word, government invites customers to be the investors of national renewable energy plan. Further, the study to model more comprehensive with a response from dynamic cost of electricity, to compare this with varied regulation, to identify the economic parameter sensitivity, to model the type of contract as well as any modification of P2P mechanism.

\section{Acknowledgment}

This research was supported and funded by PITTA grant, number: NKB0460/UN2.R3.1/HKP.05.00/2019, University of Indonesia.

\section{REFERENCES}

[1] World Energy Council. World Energy Trilemma 2017. London: World Energy Council, 2017.

[2] Long, C, Wu, J, Zhang, C, Cheng, M, Al-Wakeel, A. Feasibility of peer-to-peer energy trading in low voltage electrical distribution networks. Energy Procedia 2017; 105: 2227-2232. DOI : 10.1016/j.egypro.2017.03.632

[3] Long, C, Wu, J, Zhou, Y, Jenkins, N. Peer-to-peer energy sharing through a two-stage aggregated battery control in a community Microgrid. Applied Energy 2018; 226: 261-276. DOI: 10.1016/j.apenergy.2018.05.097

[4] Zhang, C, Wu, J, Long, C, Cheng, M. Review of existing Peer-to-peer energy trading projects. Energy Procedia 2017; 105: 2563-2568. DOI: 10.1016/j.egypro.2017.03.737

[5] Sousa, T, Soares, T, Pinson, P, Moret, F, Baroche, T, Sorin, E. Peer-to-peer and community-based markets: A comprehensive review. Renewable and Sustainable Energy Reviews 2019; 104: 367-378. DOI: 10.1016/j.rser.2019.01.036

[6] Roy, A, Bruce, A, MacGill, I. The potential value of peer-to-peer energy trading in the Australian national electricity market. In: APSRC 2016 Asia Pacific Solar Research Conference; 29 November- 1 December 2016: Australian PV Institute

[7] IRENA. Electricity Storage and Renewables: Costs and Markets to 2030. Abu Dhabi: IRENA, 2017.

[8] Park, C, Yong, T. Comparative review and discussion on P2P electricity trading. Energy Procedia 2017; 128: 3-9. DOI: 10.1016/j.egypro.2017.09.003

[9] Leberer P. Impact of P2P power trading on rooftop PV in Alberta. Aalborg: Faculty Engineering and Science Aalborg University, 2018.

[10] Beatty R. Microgrids blockchain and peer to peer. Electricity Authority of New Zealand, 2017.

[11] Zhang C. Peer-to-Peer Energy Trading in Electrical Distribution Networks. Cardiff: School of Engineering Cardiff University, 2017, UK, Ph.D.Thesis.

[12] Typpi, T. Game theory in peer-to-peer networks. Seminar on Internetworking; April 2009. Retrieved on 26 July 2020 in URL: http://citeseerx.ist.psu.edu/viewdoc/download?doi=10.1.1.500.243\&rep=rep1\&type=pdf

[13] Nguyen, S, Peng, W, Sokolowski, P, Alahakoon, D, Yu, X. Optimizing rooftop photovoltaic distributed generation with battery storage for peer-to-peer energy trading. Applied Energy 2018; 228: 2567-2580. DOI: 10.1016/j.apenergy.2018.07.042

[14] Zhang, C, Wu, J, Cheng, M, Zhou, Y, Long, C. A bidding system for peer-to-peer energy trading in a gridconnected microgrid. Energy Procedia 2016; 103: 147-152. DOI: 10.1016/j.egypro.2016.11.264

[15] Zhang, C, Wu, J, Zhou, Y, Cheng, M, Long, C. peer-to-peer energy trading in a microgrid. Applied Energy 2018; 220: 1-12. DOI: 10.1016/j.apenergy.2018.03.010 
[16] Werth, A, Andre, A, Kawamoto, D., Morita, T, Tajima, S, Tokoro, M, Yanagidaira, D, Tanaka, K. Peer-toPeer control system for DC microgrid. IEEE Transactions on Smart Grid 2018; 9(4): 3667-3675. DOI: 10.1109/TSG.2016.2638462

[17] Takur, S, Breslin, J. Peer to Peer energy trade among microgrids using blockchain based distributed coalition formation method. Technol Econ Smart Grids Sustain Energy 2018; 3: 5. DOI: 10.1007/s40866-018-0044-y

[18] Moret, F, Baroche, T, Sorin. Negotiation algorithms for peer-to-peer electricity markets: Computational Properties. In: PSCC 2018 Power Systems Computation Conference; 11-15 June 2018: Curran Associates. DOI: 10.23919/PSCC.2018.8442914

[19] Sorin, E, Bobo, L, Pinson, P. Consensus-based approach to peer-to-peer electricity markets with product differentiation. Power Systems IEEE Transactions 2019; 34(2): 994-1004. DOI : 10.1109/TPWRS.2018.2872880

[20] Nguyen, V, Besanger, Y, Tran, Q, Le, M. On the applicability of distributed ledger architectures to peer-topeer energy trading framework. IEEE EEEIC 2018, June 2018. DOI: 10.1109/EEEIC.2018.8494446

[21] Hawa, M, As-Sayid-Ahmad, L, Khalaf, L. On enhancing reputation management using Peer-to-Peer interaction history. Peer-to-Peer Networking and Applications 2013, 6, 101-113. DOI: 10.1007/s12083-0120142-X

[22] Fan J. Life Cycle Assessment and Life Cycle Cost of Photovoltaic Panels on Lake Street Parking Garage. Colorado: Colorado State University, 2014.

[23] Internet Web-Site: https://microgridknowledge.com/blockchain-energy-trading-australia/, Major Australian Retailer Trials Peer-to-Peer Energy Trading. 22 Sep. 2017.

[24] Barkai D. Peer-to-peer computing: technologies for sharing and collaborating on the net. Hillsboro, Hillsboro: Intel Press, 2001.

[25] Internet Web-Site: https://www.dsi.unive.it/ marek/files/04.55\%20-\%20peertopeer, Peer to Peer System. What is behind the buzzword?, 15 Sep. 2007.

[26] Steinmetz R, Wehrle K. Peer-to-Peer Systems and Applications. Springer, 2005.

[27] Moon, H, Miao, L, Hanks, L \& Line, N. Peer-to-peer interactions: Perspectives of Airbnb guests and hosts. International Journal of Hospitality Management 2019, 77, 405-414. DOI: 10.1016/j.ijhm.2018.08.004

[28] Zhou, Y, Wu, J., Long, C. Evaluation of peer-to-peer energy sharing mechanisms based on a multiagent simulation framework. Applied Energy 2018; 222: 993-1022. DOI: 10.1016/j.apenergy.2018.02.089

[29] Thakkar A. How Blockchain and Peer-to-Peer Energy Markets Could Make Distributed Energy Resources More Attractive. Duke University.

[30] Marzal, S, González-Medina, R, Salas-Puente, R, Figueres, E, Garcerá, G. A novel locality algorithm and peer-to-peer communication infrastructure for optimizing network performance in smart microgrids. Energies 2017, 10, 1275. DOI:10.3390/en10091275

[31] Abdelhady, S, Borella, D, Santori, S. Economic feasibility of small wind turbines for domestic consumers in Egypt based on the new feed-in tariff. Applied Energy 2015; 75: 664-670. DOI: 10.1016/j.egypro.2015.07.482

[32] Internet Web-Site: re.jrc.ec.europa.eu/pvg_tools/en/tools.html\#TMY, Photovoltaic Geographical Information System, 31 May 2019.

[33] Internet Web-Site: https://www.sia-partners.com/en/news-and-publications/from-our-experts/peer-peer-p2penergy-threat-or-opportunity-traditional, SIA Energy: Peer-to-peer (P2P) energy: A threat or an opportunity for traditional suppliers?, 11 Sep. 2018.

[34] Zhou, Y, Wu, J, Long, C, Cheng, M, Zhang, C. Performance evaluation of peer-to-peer energy sharing model. Energy Procedia 2017; 143: 817-822. DOI: 10.1016/j.egypro.2017.12.768

[35] Geremew H. A Study of Thermodynamic Modelling and Gas Extraction System Design for Aluto Langano Geothermal Power Plant II in Ethiopia. United Nation University Geothermal Training Program Report; 10: Reykjavik: Iceland, 2012.

[36] Fath, K, Stengel, J, Sprenger, W, Wilson, HR, Schultmann, F, Kuhn, TE. A method for predicting the economic potential of (building-integrated) photovoltaics in urban areas based on hourly radiance simulations. Sol. Energy 2015; 116: 357-370. DOI: 10.1016/j.solener.2015.03.023

[37] ASEAN Centre for Energy (ACE). ASEAN LCOE in Selected Renewable Energy Technologies. Jakarta: ACE; 2016.

[38] Tambunan, J. M., Pasra, N., \& Sumander, R., Studi Pemisahan Beban Penyulang Baru SKTM GIS Pantai Indah Kapuk, Jurnal Energi \& Kelistrikan, 2017, 9(1):16-25. 


\section{APPENDIX 1}

Generic residential load profile (selected sample) in one regulated country (as example).

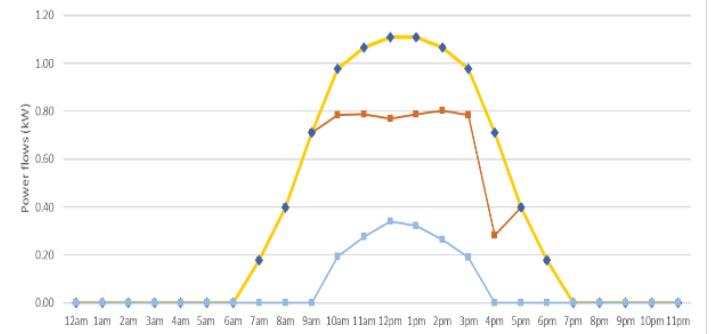

(a) solar PV+ battery - stay at home profile

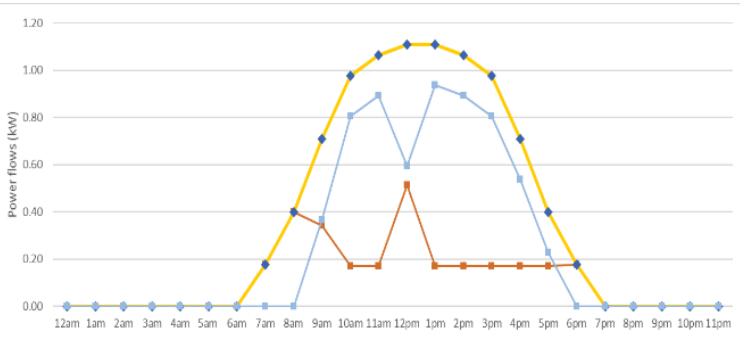

(c) solar PV + battery - nocturnal/night load profile

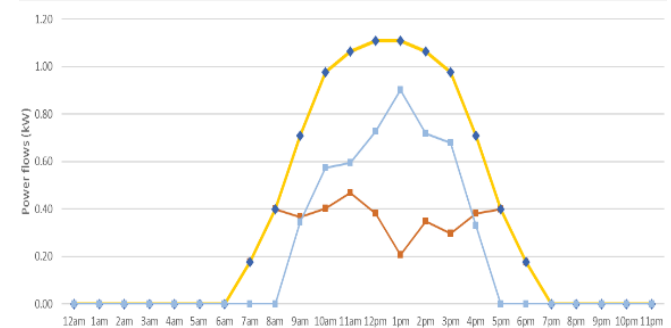

(e) solar PV + battery -morning/evening peak profile

Legends

: solar PV generation

Orange line: consumptions from solar PV generation

Blue line: Export to P2P market

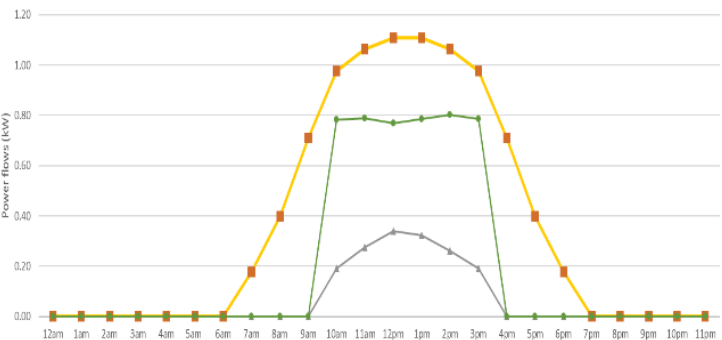

(b) either solar PV only or without solar PV+battery - stay at home profile

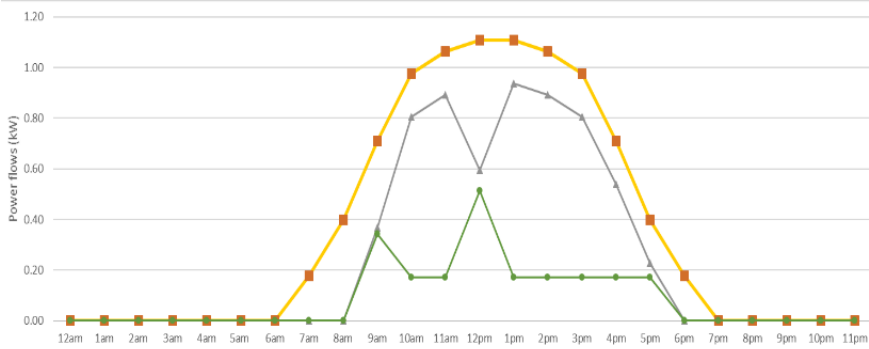

(d) either solar PV only or without solar PV+battery nocturnal/night load profile

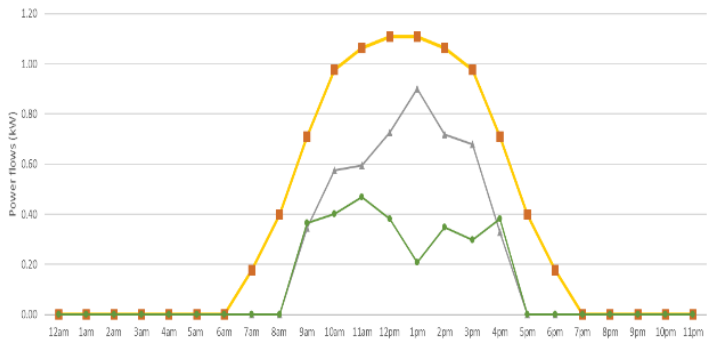

(f) either solar PV only or without solar PV+battery morning/evening peak profile

Legends

: solar PV generation

Grey line: Export due to no battery

Green line: Import from P2P market

(a-f) Load and generation profile for each type of load profile and type of participant in P2P market 